\title{
Anemia in Hospitalized Patient: Prevalence, Etiology and Risk Factors
}

Farhat Bashir, Ayesha Nageen, Saera Suhail Kidwai, Shahdil Zulfikar, Sehar Shiraz, Jamal Ara

\section{ABSTRACT}

BACKGROUND: Anemia is seen in a large proportion of the population especially in developing countries. It poses a major challenge to improving the health indices especially in the female and pediatric populations. Anemia causes increased disability, morbidity and mortality. Presence of anemia prolongs hospital stay and increases the possibility of re-admission. The diagnosis and management of anemia in hospitalized patients will improve outcomes of this population.

OBJECTIVE: The objective of this study was to determine the prevalence of anemia, its etiology and its association with various risk factors.

STUDY DESIGN: Cross-sectional study.

PLACE AND DURATION OF STUDY: Department of Medicine, United Medical and Dental College, Karachi from May, 2016 to December, 2016.

METHODOLGY: All adult patients admitted in the medical wards of Creek General Hospital were included in the study. Anemia was defined as a hemoglobin of $<13 \mathrm{~g} / \mathrm{dl}$ in males and $<12 \mathrm{~g} / \mathrm{dl}$ in females. All anemic patients were taken as cases while non-anemic patients were taken as controls. Critically ill patients, patients with active bleeding and pregnant women were excluded from the study. The data was recorded on a detailed proforma, and the etiology, severity, type of anemia and associated factors were recorded. The data was presented as means with standard deviation for continuous variables and as percentages for categorical variables. Comparison of different factors with anemia was computed using SPSS 20.0. Chi-square and student $t$ - test were used and $p$-value of $<0.05$ was considered significant.

RESULTS: Around $71 \%$ of the patients were found to be anemic. $72.5 \%$ of the female population and $67 \%$ of the male population were anemic. The commonest cause of anemia was infection. Majority of the women had microcytic anemia. There was no relationship of age, income, educational status, number of dependents and diet on the presence of anemia. In women anemia was significantly related to breast feeding and parity. Infectious diseases, nutritional deficiency and gastrointestinal loss were the most common causes of anemia in the studied population.

CONCLUSION: Anemia is very common in hospitalized medical patients. Infection and nutritional deficiencies are the most cause of this anemia.

KEY WORDS: Anemia, Infection, Nutritional deficiency, In-patients, Hospitalized.

This article may be cited as: Bashir F, Nageen A, Kidwai SS, Zulfikar S, Shiraz S, Ara J. Anemia in Hospitalized Patient: Prevalence, Etiology and Risk Factors. J Liaquat Uni Med Health Sci. 2017;16(02):80-5. doi: 10.22442/jlumhs.171620511

\section{INTRODUCTION}

According to World Health Organization anemia is defined as decrease in hemoglobin level of blood below the normal hemoglobin level of less than $13 \mathrm{~g} / \mathrm{dl}$ in males and less than $12 \mathrm{~g} / \mathrm{dl}$ in non-pregnant females ${ }^{1}$. Anemia has global presence, affecting both genders and all ages, but it affects lower socioeconomic population more due to lack of resources and deficiencies in diet. The etiology of anemia is often multifactorial. There are many conditions predisposing to anemia like nutritional deficiency, infections, blood loss, hemolysis, aplastic anemia, malignancies and anemia associated with chronic diseases like rheumatoid arthritis, chronic liver disease, chronic renal disease and endocrinal diseases ${ }^{2,3,4}$. Anemia should be taken as an indicator of underlying pathology ${ }^{5}$.

Concurrent anemia increases mortality and morbidity in the admitted patient.There is evidence that co-existing anemia prolonged hospital stay and increased re-admission rates. Although moderate and severe anemia has the most impact even mild anemia reduces work output and causes fatigue ${ }^{6}$. Anemia has a great effect on the health and life expectancy of the affected subject. This effect has been observed in specific populations like the pediatric ${ }^{7}$, pregnant ${ }^{8,6}$, geriatric and surgical ${ }^{9}$ patients; and in subjects 
suffering from certain co-morbid conditions like chronic kidney disease ${ }^{10}$, diabetes mellitus ${ }^{11}$, cardiac failure $^{12}$. The impact of anemia is not only because of its etiology but also because of its effect on susceptibility to disease, recovery and productivity ${ }^{7,13}$. The prevalence of anemia in the general population has reduced over the years by improvement in the nutrition and control of the infective causes of anemia. But the reduction is not evident in the developing countries because of a growing population. While in the developed countries, the prevalence of anemia has increased in the elderly population because of the increase in co-morbids like hypertension and chronic kidney disease. These conditions are associated with predisposition to develop anemia ${ }^{14}$.

The outcomes in the hospitalized population can be improved by management of the anemia along with the management of the primary cause of admission. The management of anemia will be based on confirming the cause and then planning the management based on the etiology.

This study was conducted to evaluate the prevalence of anemia, its types and etiology and its relationship with various risk factors in hospitalized patients.

\section{MATERIALS AND METHODS}

A cross-sectional study was carried out at Creek General Hospital, United Medical and Dental College, Karachi from May, 2016 to December 2016. Ethical approval was obtained from the review committee. Data was collected on a planned proforma after the participant's consent. All adult patients admitted to the Medical Wards of the hospital were included in the study. The anemic patients were taken as cases and non-anemic patients were taken as controls. Critically ill patients, those with active bleeding and pregnant patients were excluded from the study. Preliminary blood tests were done with $5 \mathrm{ml}$ venous blood including full counts by automated method (MEDONIC). Other relevant investigations to diagnose the cause of anemia were carried outas indicated. These investigations included peripheral smear, liver and renal function tests, iron profile, serum vitamin B12 levels, RBC folate levels, serological tests for coeliac disease, upper or lower gastrointestinal endoscopy with biopsy, serum lactate dehydrogenase levels, Coomb's test, hemoglobin electrophoresis, bone marrow biopsy, endocrinal profile and radiological investigations.

The blood hemoglobin concentration was done in all cases as screening test for anemia. The patient with hemoglobin less than $13 \mathrm{~g} / \mathrm{dl}$ in male and $12 \mathrm{~g} / \mathrm{dl}$ in female were labeled as anemic as defined by WHO criteria. Mild, moderate and severe anemia was also determined according to WHO criteria. In non-pregnant females mild anemia was taken as hemoglobin level of $11 \mathrm{~g} / \mathrm{dl}$ to $11.9 \mathrm{~g} / \mathrm{dl}$, moderate anemia as $8 \mathrm{~g} / \mathrm{dl}$ to $10.9 \mathrm{~g} / \mathrm{dl}$ and severe anemia as $<8 \mathrm{~g} / \mathrm{dl}$. In male subjects mild anemia was defined as a hemoglobin level of $11 \mathrm{~g} / \mathrm{dl}$ to $12.9 \mathrm{~g} / \mathrm{dl}$, moderate anemia as $8 \mathrm{~g} / \mathrm{dl}$ to $10.9 \mathrm{~g} / \mathrm{dl}$ and severe anemia as $<8$ $\mathrm{g} / \mathrm{dl}^{15}$. Type of anemia and its cause was determined for every patient.

Collected data had been entered and statistically analyzed on the SPSS version 20.0. Mean and standard deviation was computed for quantitative variables. The frequencies and percentages of categorical variables were computed. Pearson's Chi square test was used to compare categorical variables. Student t- test was used to compare continuous variables. P-value of $<0.05$ was considered significant.

\section{RESULTS}

Two hundred and twenty five patients, admitted in the medical wards during this period were included in the study. There were 76 (34\%) males and 149(66\%) females with a mean age of $43.1 \pm 16.6$ for males and $40.5 \pm 16.1$ years for females. Mean hemoglobin was $10.96 \pm 2.2 \mathrm{~g} / \mathrm{dl}$ in the whole population; it was 10.6 $\pm 2.1 \mathrm{~g} / \mathrm{dl}$ in female and $11.49 \pm 2.4 \mathrm{~g} / \mathrm{dl}$ in male. Mean hemoglobin level was significantly lower ( $p$-value $<0.01$ ) in females as was MCV (p-value <0.01). Although $\mathrm{MCH}$ was also lower in females but this value was not statistically significant ( $p$-value $<0.054)$. Microcytic anemia was significantly more prevalent in females ( $p$-value<0.00) (Table- - ).

Although a higher percentage of females was found to have anemia but the presence of anemia was not significantly associated with gender. Presence of anemia was not significantly associated with the female gender $(p$-value $<0.44)$. There was also no association of anemia with the age group, dietary habits or income bracket (Table-II).

The cause of anemia was found to be infection in $27.7 \%$ of the patients, malaria and gastrointestinal causes were responsible for 23.3 and $11.7 \%$ of the anemia burden respectively while iron deficiency accounted for $10.7 \%$ of the anemia (Figure-I).

Parity was not significantly associated with anemia but breast feeding showed a significant association with anemia in the female population (Figure II \& III). 
Farhat Bashir, Ayesha Nageen, Saera Suhail Kidwai, Shahdil Zulfikar, Sehar Shiraz, Jamal Ara

TABLE I: GENDER DIFFERENCES IN HOSPITALIZED ANEMIC PATIENTS

\begin{tabular}{|c|c|c|c|c|}
\hline \multicolumn{2}{|c|}{ Variable } & $\begin{array}{c}\text { Male } \\
\text { population } \\
\mathrm{n}=76 \\
(34 \%)\end{array}$ & $\begin{array}{c}\text { Female } \\
\text { population } \\
n=149 \\
(66 \%)\end{array}$ & p-value \\
\hline \multicolumn{2}{|l|}{ AGE } & $43.18 \pm 16.64$ & $40.5 \pm 16.1$ & $0.25^{*}$ \\
\hline \multirow{5}{*}{$\begin{array}{l}\text { EDUCA- } \\
\text { TIONAL } \\
\text { STATUS }\end{array}$} & Illiterate & $9(20 \%)$ & $40(35.4 \%)$ & \multirow{5}{*}{$0.42 \pi$} \\
\hline & Primary & $17(37.8 \%)$ & $36(31.9 \%)$ & \\
\hline & Secondary & $16(35.6 \%)$ & $26(23 \%)$ & \\
\hline & Graduate & $3(6.7 \%)$ & $10(8.8 \%)$ & \\
\hline & Postgraduate & - & $1(0.9 \%)$ & \\
\hline \multicolumn{2}{|c|}{ INCOME(Rs) } & $\begin{array}{l}19086 \\
\pm 11765\end{array}$ & $24008 \pm 21973$ & $0.13^{*}$ \\
\hline \multicolumn{2}{|c|}{ NO OF DEPENDANTS } & $6.95 \pm 3.5$ & $6.2 \pm 3.59$ & $0.39^{*}$ \\
\hline \multicolumn{2}{|c|}{ MEAT/WEEK } & $2.46 \pm 1.6$ & $2.5 \pm 1.5$ & $0.99^{*}$ \\
\hline \multicolumn{2}{|l|}{ WEIGHT } & $62.98 \pm 15.7$ & $59.1 \pm 14.8$ & $0.18^{*}$ \\
\hline \multicolumn{2}{|c|}{ HEMOGLOBIN } & $11.49 \pm 2.4$ & $10.6 \pm 2.1$ & $0.01^{*}$ \\
\hline \multicolumn{2}{|l|}{ MCV } & $82.6 \pm 14.0$ & $78.5 \pm 9.5$ & $0.01^{*}$ \\
\hline \multicolumn{2}{|l|}{$\mathrm{MCH}$} & $28.0 \pm 8.6$ & $26 \pm 6.29$ & $0.54^{*}$ \\
\hline \multirow{3}{*}{$\begin{array}{l}\text { Type of } \\
\text { anemia }\end{array}$} & microcytic & $26(34.2 \%)$ & $80(53.7 \%)$ & \multirow{3}{*}{0.009} \\
\hline & normocytic & $42(55.3 \%)$ & $68(45.6 \%)$ & \\
\hline & macrocytic & $8(10.5 \%)$ & $1(0.7 \%)$ & \\
\hline
\end{tabular}

*=Student $t$ test, $\mathfrak{T}=$ Chi square test

FIGURE I: CAUSES OF ANEMIA IN HOSPITALIZED PATIENTS

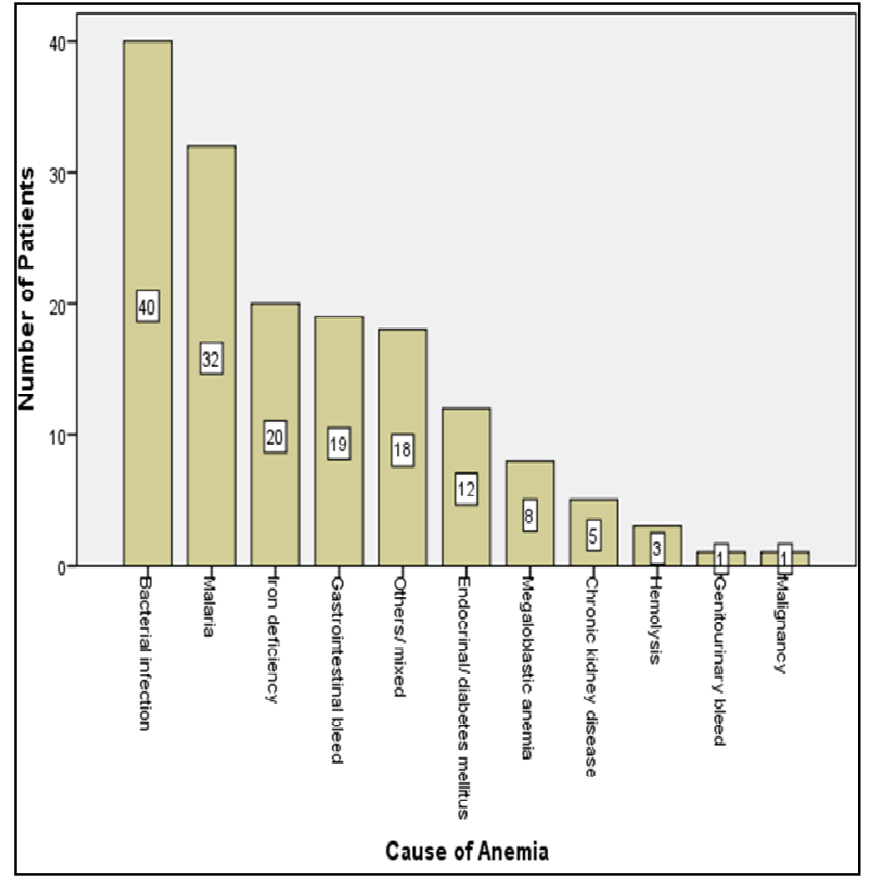

FIGURE II: ASSOCIATION OF PARITY AND ANEMIA IN FEMALE SUBJECTS ( $p$-value<0.14)

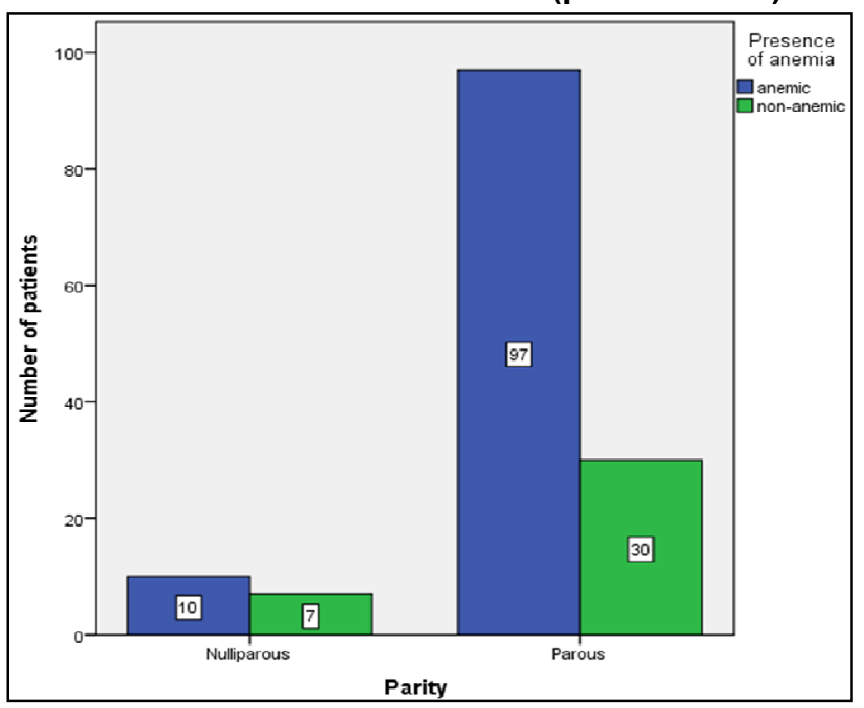

FIGURE III: BREAST FEEDING AND ANEMIA IN FEMALE SUBJECTS

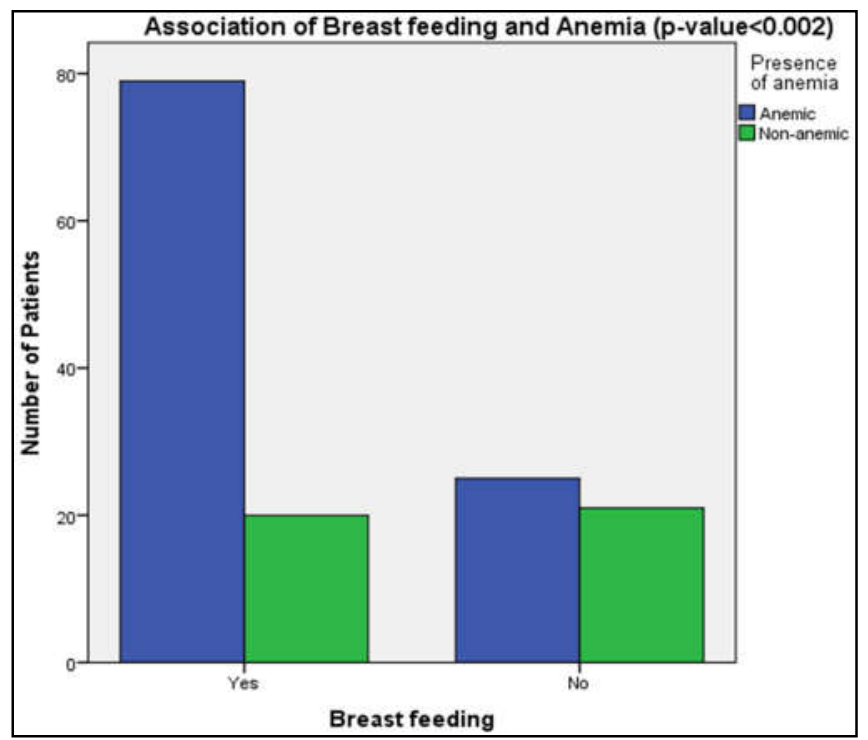

\section{DISCUSSION}

Our study re-emphasizes the fact that anemia is very prevalent in the admitted patients. In our study anemia was seen in almost $70 \%$ of the population under study. As seen in other studies this prevalence was higher in females $(72.5 \%)$ than in males $(67.1 \%)$. The important point is that the association of anemia with gender was not significant. In hospitalized patients male patients are also susceptible to development of anemia. World Health Organization has reported that $24.8 \%$ of the general population is anemic. The prevalence of anemia among females $(30.2 \%)$ is higher than among males $(12.7 \%)^{1}$. Anemia is common among the very young, females ${ }^{16}$ and the 
Anemia in Hospitalized Patient

TABLE II: ASSOCIATION OF VARIABLES WITH ANEMIA IN HOSPITALIZED PATIENTS

\begin{tabular}{|c|c|c|c|c|c|}
\hline \multicolumn{2}{|c|}{ VARIABLE } & $\begin{array}{c}\text { Whole } \\
\text { population } \\
(n=225)\end{array}$ & $\begin{array}{c}\text { Anemic } \\
\text { population } \\
(n=159)\end{array}$ & $\begin{array}{c}\text { Non-anemic } \\
\text { population } \\
(n=66)\end{array}$ & p-value \\
\hline \multicolumn{2}{|c|}{ AGE (years)mean $\pm S D$} & $41.4 \pm 16.3$ & $41.1 \pm 16.1$ & $42 \pm 16.8$ & $0.73^{*}$ \\
\hline \multirow{4}{*}{$\begin{array}{l}\text { Age group } \\
\text { Number(\%) }\end{array}$} & $>20$ years & $25(11 \%)$ & $19(12 \%)$ & $6(9 \%)$ & \multirow{4}{*}{$0.34 \pi$} \\
\hline & $21-40$ years & $88(40 \%)$ & $57(37 \%)$ & $31(47 \%)$ & \\
\hline & $41-60$ years & $76(34 \%)$ & $58(37.4 \%)$ & $18(27 \%)$ & \\
\hline & $<60$ years & $32(15 \%)$ & $21(13.6 \%)$ & $11(17 \%)$ & \\
\hline \multirow{2}{*}{$\begin{array}{l}\text { GENDER } \\
\text { Number(\%) }\end{array}$} & MALE & $76(34 \%)$ & $51(67 \%)$ & $25(33 \%)$ & \multirow{2}{*}{$0.44 \rrbracket$} \\
\hline & FEMALE & $149(66 \%)$ & $108(72.5 \%)$ & $41(27.5 \%)$ & \\
\hline \multirow{5}{*}{$\begin{array}{l}\text { EDUCATIONAL } \\
\text { STATUS } \\
\text { Number }(\%)\end{array}$} & Illiterate & $49(31 \%)$ & $19(12.3 \%)$ & $19(38 \%)$ & \multirow{5}{*}{$0.418 \pi$} \\
\hline & Primary & $53(33.5 \%)$ & $57(36.4 \%)$ & $14(28 \%)$ & \\
\hline & Secondary & $42(26.6 \%)$ & $58(37.4 \%)$ & $14(28 \%)$ & \\
\hline & Graduate & $13(8.2 \%)$ & $21(13.5 \%)$ & $2(4 \%)$ & \\
\hline & postgraduate & $1(.6 \%)$ & 0 & $1(2 \%)$ & \\
\hline \multicolumn{2}{|l|}{ INCOME(Rs) } & $22476 \pm 19476$ & $22098 \pm 18711$ & $23360 \pm 21331$ & $0.070^{*}$ \\
\hline \multirow[t]{2}{*}{ Income group } & $>25,000$ & $85(57 \%($ & $59(56.2 \%)$ & $26(59 \%)$ & $0.85 \pi$ \\
\hline & $<25,000$ & $64(43 \%)$ & $46(43.8 \%)$ & $18(41 \%)$ & \\
\hline \multicolumn{2}{|c|}{ NO OF DEPENDANTS } & $6.44 \pm 3.51$ & $6.3 \pm 3.5$ & $6.7 \pm 3.5$ & $0.45^{*}$ \\
\hline \multicolumn{2}{|l|}{ MEAT/WEEK } & $2.5 \pm 1.5$ & $2.5 \pm 1.6$ & $2.3 \pm 1.3$ & $0.34^{*}$ \\
\hline \multicolumn{2}{|l|}{ WEIGHT(kg) } & $60.2 \pm 15$ & $58.4 \pm 14.3$ & $64.2 \pm 16.3$ & $0.04^{*}$ \\
\hline \multicolumn{2}{|c|}{ HEMOGLOBIN (g/dl) } & $10.96 \pm 2.23$ & $10.05 \pm 1.87$ & $13.1 \pm 1.4$ & $0.01^{*}$ \\
\hline \multicolumn{2}{|l|}{$\mathrm{MCV}(\mathrm{fl})$} & $79.9 \pm 11.3$ & $78.14 \pm 12.04$ & $84 \pm 8$ & $0.01^{*}$ \\
\hline \multicolumn{2}{|l|}{$\mathrm{MCH}(\mathrm{pg})$} & $26.7 \pm 7.2$ & $26.5 \pm 8.3$ & $27.2 \pm 3.2$ & $0.54^{*}$ \\
\hline
\end{tabular}

elderly. Although usually women are known to be a vulnerable population, we need to be aware that sick people are at higher risk of having anemia regardless of gender. Anemia has been observed in women in almost all regions, the improvement in anemia indices observed globally, is more in males as compared to females. Therefore the female population is still more susceptible to the development of anemia. Prevalence of anemia in the general female Indian population was found to be $52 \%$. Malnutrition, high prevalence of infective causes and multi-parity contributed to this high prevalence. In our study the majority of the anemic females belonged to the reproductive age group and the presence of anemia was significantly associated with breast feeding and parity.
There was no statistically significant difference between different age groups and presence of anemia but anemia was commoner in younger females and in elderly males. This finding highlights the role of parity and breastfeeding in the development of anemia in females. In our study most of the anemic patients belonged to age groups of 20-40 and 40-60 years. Income level, educational status, dietary habits and number of dependents in the family was not significantly different in relation to gender. Microcytic hypochromic anemia was seen most frequently in females $(53 \%)$ than in males $(34.2 \%)$ and this difference was statistically significant.

In hospitalized populations anemia has been evaluated in certain specific populations. In chronically 
ill patients anemia is very common. In dialysis dependent children hemoglobin was seen to be 9.2 $\pm 1.8 \mathrm{~g} / \mathrm{dl}$. Around $47 \%$ of children with renal failure in a UK study had anemia. In patients with chronic liver disease anemia was seen in $30-70 \%$ of the patients. Around $50 \%$ of the post renal transplant patients and majority of the cancer patients were found to be anemic $^{17}$.

Patients with chronic illness are more prone to have anemia either because of the effect of the disease, side effects of the medication or constitutional anorexia which accompanies the disease process.

The alarming thing is that although it is documented that concomitant anemia increases mortality in all patients, appropriate investigations and intervention for the treatment of anemia are not generally undertaken. This is because in the hospitalized patient the major concern is the management of the cause of admission or the primary disease. While anemia is considered to be a complication of the treatment or a part of the disease process. Thus focus of management is on the primary cause and the patient may even be discharged without being investigated or treated for the anemia. The greater the length of hospital stay the greater the chance of more significant decrease in hemoglobin values. Thus focus on anemia management should be a part of the protocol.

The presence of anemia in such a large proportion of hospitalized patients also indicates the borderline hemoglobin levels or mild anemia in the general population ${ }^{6}$. There is such a small reserve that any illness leads to decompensation of the fine balance being maintained by body which leads to development of anemia and also increased severity of disease so that the patient requires admission.

A high reproductive cycling also contributes to either deficiency or depleted stores. The effect of economic status on presence of anemia is not significant. Therefore anemia does not differentiate between poor and middle class especially among the hospitalized patients. The anemic patients were significantly underweight as compared to the non-anemic patients in our study. Under-nourished subjects are at higher risk of developing anemia as compared to a better nourished population. The people in urban populations are malnourished but not undernourished. The cooking habits and the dietary habits need to be improved for achieving a balanced diet. This will improve the overall health statistics.

Infections and malaria accounted for the vast majority of both admission and anemia in the study population. Chronic infection is also a factor for chronic inflammatory response ${ }^{18}$ and micronutrient deficiency adds to this, leading to development of anemia.

The global reduction of anemia has been mainly due to control of hook worm infestation and control of post-partum hemorrhage ${ }^{19}$. Control of malaria in some regions has led to a lower prevalence of anemia in those areas ${ }^{20}$. But in areas where malaria is rampant anemia prevalence has increased ${ }^{21}$. Chronic illnesses like diabetes and hypertension leading to chronic kidney disease are contributing to anemia in high income areas. Malaria was seen to be the etiological factor in around $23 \%$ of the anemia cases in our study.

Gastrointestinal causes accounted for the third large portion of anemic patients highlighting the fact that hepatitis $C$ is very prevalent in Pakistan. The high prevalence of chronic hepatitis in the population and its related complications contribute to this. Helicobacter pylori infection is also present in a large majority of patients reflecting contaminated food and water. This infection leads to gastritis and peptic ulceration leading to blood loss.

The next large portion of anemic patients belonged to the nutritional iron deficiency followed by endocrinal causes including hypothyroidism and hypopituitarism (there were two patients with Sheehan's syndrome). Nutritional deficiencies are common in Pakistan because of the dietary preferences, social customs and culinary practices of the population. It is worth mentioning that iron deficiency was labeled in those patients who had a nutritional cause of this deficiency. Blood loss from any site or malabsorption of iron due to reasons such as coeliac disease was included in the etiological classification related to that specific system. Diabetes mellitus has assumed an alarming prevalence in Pakistan. It is not well controlled in the majority of patients and its multiple complications including nephropathy is contributing towards anemia in the admitted patients. Nutritional iron deficiency is seen mostly in low income areas, while in high income areas hemoglobinopathies, CKD and gastrointestinal hemorrhage cause anemia in the majority of cases ${ }^{17}$. Anemia can be a part of the presenting features of a hospitalized patient and it may also emerge during hospital stay. Infection, inflammation, frequent blood sampling, stress gastritis, nutritional deficiencies, renal failure, effects of certain drugs and different invasive procedures can lead to development of anemia. Trials to clarify the therapy for correction of anemia are required ${ }^{22}$. Comprehensive management of all issues will improve outcomes in the hospitalized patients.

\section{CONCLUSION}

- Anemia is very common in the hospitalized patients and the most common cause is infection including malaria.

- The treatment of anemia will improve outcome in hospitalized patients. Proper management will 
require accurate diagnosis and targeted therapy.

\section{REFERENCES}

1. WHO. De Benoist B, McLean E, Egli I, Cogswell M. Worldwide Prevalence of Anaemia 1993-2005. WHO Global Database on Anaemia. 2008: WHO Press; Geneva.

2. Camaschella C. Iron-Deficiency Anemia. N Engl J Med 2015; 372(19):1832-43.

3. Powers JM, Buchanan GR. Diagnosis and management of iron deficiency anemia. Hematol Oncol Clin North Am 2014; 28(4):729-45.

4. Sakiewiez P, Paganini E. The use of iron in patients on chronic dialysis: mistake and misconceptions.J Nephrol 1998; 11(1):5-15.

5. Shrivastava SR, Hippargi SB, Yelikar BR. Pattern of anemia in Geriatric Age Group. JKIMSU 2013; 2(1): 77-81.

6. Bentley ME, Griffiths PL. Anemia burden for Indian women. Eur J Clin Nutr 2003;57(1): 52-60.

7. Brabin BJ, Premji Z, Verhoeff F. An analysis of anemia and child mortality. J Nutr. 2001; 131(2S2):636S-645S.

8. Rasmussen K. Is there a causal relationship between iron deficiency or iron-deficiency anemia and weight at birth, length of gestation and perinatal mortality? J Nutr. 2001; 131(2S-2):590S $-601 S$.

9. Dunne JR, Malone D, Tracy JK, Gannon C, Napolitano LM. Perioperative anemia: an independent risk factor for infection, mortality, and resource utilization in surgery. J Surg Res. 2002; 102(2):237-44.

10. Shams N, Osmani MH. Newly Diagnosed Anemia in Admitted Diabetics, Frequency, Etiology and Associated Factors, J Coll Physicians Surg Pak 2015; 25 (4): 242-246.

11. Sharif A, Younus S, Baig K, Ali N. Prevalence and Risk of Anemia in Type-2 Diabetic Patients. Health 2014; 6: 1415-1419.

12. Anand IS. Anemia and chronic heart failure implications and treatment options. J Am Coll Cardiol. 2008; 52(7):501-11.

AUTHOR AFFILIATION:

Dr. Farhat Bashir (Corresponding Author)

Associate Professor, Department of Medicine

United Medical and Dental College Karachi, Sindh-Pakistan.

E-mail: drfarhartbashir@gmail.com

Dr. Ayesha Nageen

Assistant Professor, Department of Medicine

United Medical and Dental College Karachi, Sindh-Pakistan.

Dr. Saera Suhail Kidwai

Associate Professor, Department of Medicine

United Medical and Dental College Karachi, Sindh-Pakistan.
13. Glazer Y, Bilenko N. Effect of iron deficiency and iron deficiency anemia in the first two years of life on cognitive and mental development during childhood. Harefuah. 2010; 149(5):309-14.

14. Rachoin JS, Cerceo E, Milcarek B, et al. Prevalence and Impact of Anemia in Hospitalized Patients. South Med J. 2013;106(3):202-6.

15. WHO. Haemoglobin concentrations for the diagnosis of anaemia and assessment of severity. Vitamin and Mineral Nutrition Information System. Geneva, World Health Organization, 2011(WHO/ $\mathrm{NMH} / \mathrm{NHD} / \mathrm{MNM} / 11.1$ ) available from: http:// www.who.int/vmnis/indicators/haemoglobin.pdf.

16. Stevens GA, Finucane MM, De-Regil LM, et al. Global, regional, and national trends in haemoglobin concentration and prevalence of total and severe anaemia in children and pregnant and non -pregnant women for 1995-2011: a systematic analysis of population-representative data. Lancet Glob Health 2013; 1(1): e16-e25.

17. Spence RK. Medical and economic impact of anemia in hospitalized patients. Am J Health Syst Pharm. 2007; 64(16 Suppl 11):S3-10.

18. Knight K, Wade S, Balducci L. Prevalence and outcomes of anemia in cancer: a systematic review of the literature. Am J Med. 2004; 116 (Suppl 7A):11S-26S.

19. Kassebaum NJ, Jasrasaria R, Naghavi M, et al. A systematic analysis of global anemia burden from 1990 to 2010. Blood. 2014;123(5):615-24.

20. Korenromp EL, Armstrong-Schellenberg JR, Williams BG, et al. Impact of malaria control on childhood anaemia in Africa-a quantitative review. Trop Med Int Health. 2004; 9(10):105065.

21. Gething PW, Patil AP, Smith DL, et al. A new world malaria map: Plasmodium falciparum endemicity in 2010. Malaria J. 2011; 10: 378-394.

22. McLennan JD, Steele M. Anemia Screening and Treatment Outcomes of Children in a Low-resource Community in the Dominican Republic. J Trop Pediatr 2016; 62(2): 116-22.

Shahdil Zulfikar

Student $3^{\text {rd }}$ Year MBBS,

United Medical and Dental College Karachi, Sindh-Pakistan.

Sehar Shiraz

Student $3^{\text {rd }}$ Year MBBS

United Medical and Dental College Karachi, Sindh-Pakistan.

Prof. Jamal Ara

Department of Medicine

United Medical and Dental College Karachi, Sindh-Pakistan. 